\title{
Numerical Analysis of PAGE Protein Patterns and the Taxonomic Relationships within the 'Mycoplasma mycoides Cluster'
}

\author{
By M. COSTAS, ${ }^{1 *}$ R. H. LEACH ${ }^{2}$ AND D. L. MITCHELMORE ${ }^{2}$ \\ National Collection of Type Cultures, ${ }^{1}$ and PHLS Mycoplasma Reference Facility, NCTC, ${ }^{2}$ \\ Central Public Health Laboratory, Colindale Avenue, London NW9 5HT, UK
}

(Received 7 July 1987)

Twenty-six isolates belonging to the 'Mycoplasma mycoides cluster' have been characterized by one-dimensional SDS-PAGE of their cellular proteins. A numerical classification based on the resulting patterns and using a correlation coefficient revealed four distinct phenons at a similarity $(S)$ level of $70 \%$, comprising: (a) bovine group 7 strains; $(b) M$. capricolum and F38like strains; (c) M. mycoides subsp. capri and LC strains ('subsp. mycoides'); (d) M. mycoides subsp. mycoides (SC). At the $75 \% S$ level, they could be divided further to give eight phenons. The composition of the clusters at both levels was in good agreement with their previous classification, except for $M$. mycoides subsp. mycoides LC and $M$. mycoides subsp. capri, which were clustered in a single phenon at $70 \% \mathrm{~S}$ and could not be clearly separated at $75 \% \mathrm{~S}$. We conclude that high-resolution SDS-PAGE, combined with computerized analysis of protein patterns, provides an extremely effective approach to the investigation of taxonomic relationships within this group of mycoplasmas.

\section{INTRODUCTION}

The sub-division of the genus Mycoplasma had originally seemed a relatively simple matter, most individual species being readily separable, mainly on a serological basis (Edward \& Freundt, 1969; Freundt \& Edward, 1979). In recent years, however, taxonomic problems have arisen, as the increasing number of known mycoplasmas has led to discovery of serological crossreactivities between some presumedly separate species. Genomic comparisons have also revealed other unsuspected inter-species relationships. Within Mycoplasma, the organisms known as the 'Mycoplasma mycoides cluster' present the most prominent current taxonomic problem (Cottew et al., 1987).

The 'Mycoplasma mycoides cluster' contains mycoplasmas from cattle, sheep and goats, forming six different groups with varying degrees of genomic or antigenic inter-relationships. These groups include the named species Mycoplasma mycoides subsp. mycoides ['small-colony' (SC) strains, mainly from cattle], $M$. mycoides subsp. capri (goats) and $M$. capricolum (sheep and goats). The other three groups have uncertain taxonomic status. They include the so-called 'large-colony' (LC) strains (mainly from goats) tentatively classified as ' $M$. mycoides subsp. mycoides (LC)', being serologically indistinguishable from the SC strains although biologically quite different (Cottew \& Yeats, 1978). The two other groups in the cluster are as yet unnamed, viz. bovine serogroup 7 from cattle (Leach, 1973) and F38-related strains causing contagious pleuropneumonia in goats (Ernø et al., 1983).

The complicated relationships, biological characters and aetiological associations of the six mycoplasma groups within this cluster are described and discussed in a recent report to the ICSB Subcommittee on the Taxonomy of Mollicutes (Cottew et al., 1987). In brief, the main classification problems affecting the different members are as follows. (1) A close serological

\footnotetext{
Abbreviations: 1-D, one-dimensional; 2-D, two-dimensional; TEMED, $N, N, N^{\prime}, N^{\prime}$-tetramethylethylenediamine.
} 
relationship between the $M$. mycoides subsp. mycoides SC strains and the LC strains, which are nevertheless quite distinct in their cultural, biochemical and pathogenicity properties. (2) Potential difficulties in distinguishing between the LC group and M. mycoides subsp. capri. (3) A close genomic relationship and partial serological cross-reactivity between the $F 38$ group and $M$. capricolum and a very close serological similarity between F38 and bovine serogroup 7 strains, all three of these groups being quite distinct, however, in their general biochemical characters and in host relationships or pathogenicity.

The report to the Subcommittee (Cottew et al., 1987) has stressed the potential taxonomic usefulness of two-dimensional (2-D) electrophoretic patterns (Rodwell, 1982) in pointing towards a suitable classification for these six groups, and also the need to rely ultimately on DNA homology tests in difficult cases and as a final means of resolving taxonomic discrepancies. However, both approaches entail considerable time and effort, especially as any comparison between individual groups ought to involve several isolates of each group, rather than merely the individual type or reference strains, as has been the tendency so far (Cottew et al. 1987). The method that we have employed, a computerized numerical analysis of the onedimensional (1-D) protein patterns of several strains for each of the six groups, has the advantage that all the test strains can be compared in one gel run, enabling a comprehensive comparative analysis of up to 30 strains under standard conditions and forming a programme readily achievable in weeks rather than the many months probably required for similar comparisons by the other methods.

\section{METHODS}

Mycoplasma strains. Each of the six groups of the ' $M$. mycoides cluster' was represented by three to five strains, including type or reference strains where appropriate, and $M$. pneumoniae was included as a control organism (Table 1). Cultures were grown at $37^{\circ} \mathrm{C}$ in a liquid medium based on that of Hayflick (1965) and containing horse serum $(20 \%, v / v)$, yeast extract $(0.7 \%, w / v$, Oxoid), thallous acetate $(2.5 \%, w / v)$, glucose $(1 \%$, w/v), penicillin $\left(200 \mathrm{U} \mathrm{m}^{-1}\right)$ and phenol red $(0.002 \%, \mathrm{w} / \mathrm{v})$ in mycoplasma broth base (Oxoid) adjusted to $\mathrm{pH} 7.6$.

Culture conditions. Broth cultures of each test strain were prepared by dilution $(1 / 10, \mathrm{v} / \mathrm{v})$ of an inoculum culture and reincubation until an appreciable acid colour change was observed.

Harvesting conditions. Appropriate amounts $(25-100 \mathrm{ml})$ of test cultures were centrifuged for $30 \mathrm{~min}$ at $1300 \mathrm{~g}$. Cell deposits were washed twice with phosphate-buffered saline (PBS; Dulbecco 'A', Oxoid; pH 7.3) and centrifuged again ( $30 \mathrm{~min}, 1300 \mathrm{~g}$ ).

Preparation of protein samples. The resulting pellet was finally resuspended in about $60 \mu \mathrm{l}$ double-strength lysis buffer $120 \%(\mathrm{v} / \mathrm{v})$ glycerol, $2 \%(\mathrm{v} / \mathrm{v}) 2$-mercaptoethanol, $4 \%(\mathrm{w} / \mathrm{v})$ SDS and $70 \%(\mathrm{v} / \mathrm{v})$ stacking gel buffer, see details below]. The thoroughly mixed bacterial sample in lysis buffer was incubated in a Pierce Reacti-therm heating module (Pierce Chemical Company) at $100^{\circ} \mathrm{C}$ for $5 \mathrm{~min}$. An equal quantity of sterile distilled water was added, and the tube was agitated and then heated at $100^{\circ} \mathrm{C}$ for a further $5 \mathrm{~min}$. The sample was then centrifuged $(11600 \mathrm{~g}$ ) for $10 \mathrm{~min}$ to remove particulate matter and cellular debris. The supernatant containing water-soluble proteins was then removed carefully and stored at $-20^{\circ} \mathrm{C}$.

Electrophoresis. Discontinuous gels $(16 \times 18 \times 0.15 \mathrm{~cm})$ were cast to allow for $10 \mathrm{~mm}$ of stacking gel. The separation gel was prepared to give a final polyacrylamide content of $10 \%(w / v)$ from a stock solution containing $29.2^{\circ}(\mathrm{w} / \mathrm{v})$ acrylamide and $0.8 \%(\mathrm{w} / \mathrm{v}) \quad N, N^{\prime}$-methylenebisacrylamide $\left(30 \% \mathrm{~T}, 2.7 \% \mathrm{C}_{\mathrm{bis}}\right)$. The final concentrations of other components in the gel were $0.375 \mathrm{M}-\mathrm{Tris} / \mathrm{HCl}(\mathrm{pH} 8 \cdot 8$ : prepared by adding $87.5 \mathrm{ml} 5 \mathrm{M}$ $\mathrm{HCl}$ and made up to 1 litre with the Tris buffer solution) and $0 \cdot 1 \%(\mathrm{w} / \mathrm{v}) \mathrm{SDS}$. Polymerization was achieved by adding $0.05 \%(\mathrm{w} / \mathrm{v})$ ammonium persulphate $(10 \%, \mathrm{w} / \mathrm{v}$ solution) and $0.05 \%(\mathrm{v} / \mathrm{v})$ TEMED. The separation gel components excluding SDS were de-aerated for $3 \mathrm{~min}$ before polymerization, which took approximately $15 \mathrm{~min}$ at $20^{\circ} \mathrm{C}$. The stacking gel was prepared from the same stock solution used for the separation gel to give a polyacrylamide content of $5 \%$. The remaining stacking gel components, including the stacking gel buffer, were added to give a final concentration of $0.125 \mathrm{M}-\mathrm{Tris} / \mathrm{HCl}(\mathrm{pH} 6.8$ : prepared by adding $95 \mathrm{ml} 5 \mathrm{M}-\mathrm{HCl}$ and made up to 1 litre with the Tris buffer solution) and $0 \cdot 1 \%(w / v)$ SDS. Polymerization was initiated by adding $0.05 \%(w / v)$ ammonium persulphate $(10 \%, w / v$ solution) and $0.1 \%(v / v)$ TEMED. The stacking gel solution excluding SDS was de-aerated for $3 \mathrm{~min}$ and polymerization was evident after 6-8 $\mathrm{min}$. The well-forming comb was removed from the stacking gel after $1 \mathrm{~h}$ and the sample wells were washed twice with tank buffer [0.25 $\mathrm{M}$-Tris pH 8.3, $0.192 \mathrm{M}$-glycine, $0.1 \%(\mathrm{w} / \mathrm{v})$ SDS]. The wells were then loaded with approximately $10 \mu \mathrm{l}$ of the protein sample to which $0.001 \%$ ( $/ v$, final concn) of bromophenol blue had been added as a marker dye.

Electrophoresis was carried out for about $4 \mathrm{~h}$ in a Protean double slab vertical electrophoresis cell (Bio Rad), at a constant current of $30 \mathrm{~mA}$ per gel until the marker dye had migrated $100 \mathrm{~mm}$ along the length of the separation gel. 
Table 1. Mycoplasma strains used and sources

Ref. no. in dendrogram

1
2
3

Strain designation*

Obtained
from $\dagger$

Country of

Bovine serogroup 7

L2917
QR 1 TC $10133^{\mathrm{R}}=$ N29 $=$ PG50
NCTC

F38-like

G133 = C1668
G183
G275
NCTC $10192^{\mathrm{R}}=$ F 38

M. capricolum

PP goat
YP
YO
ZT
$74 / 3220$
$\begin{aligned} \text { NCTC } 10154^{\mathrm{T}}= & \text { California Kid } \\ & M . \text { pneumoniae }\end{aligned}$

NCTC $10119^{\mathrm{T}}=\mathbf{F H}$

M. mycoides subsp. capri

$74 / 5907 \mathrm{~A}$

$\mathrm{ZZ}$

BQT

NCTC $10137^{\top}=$ PG 3

M. mycoides subsp. mycoides (LC)

$\mathrm{Y}$ goat $^{\mathrm{R}}$

$\mathrm{M} 2055 / 75=\mathrm{F} 30$

$74 / 2488$

Cov 2

Ojo 1

M. mycoides subsp. mycoides (SC)

$\begin{array}{ll}1 & \text { Australia } \\ 1 & \text { Australia } \\ 2 & \text { Australia }\end{array}$

Kenya

Kenya

Kenya

Kenya

Turkey

Australia

Australia

Australia

Australia

USA

USA

Australia

Australia

Turkey

Turkey

Australia

Kenya

Australia

Turkey

Nigeria

Australia

Kenya

Sudan

- $T$, type strain; $R$, reference strain for designated taxon.

$\dagger$, G. S. Cottew, CSIRO, Division of Animal Health, Parkville, Victoria, Australia; 2, National Collection of Type Cultures, Colindale, London, UK ; 3, H. Ernø, Institute of Medical Microbiology, University of Aarhus, Aarhus, Denmark; 4, G. R. Smith, Institute of Zoology, Regents Park, London, UK; 5, K. J. MacOwan, Central Veterinary Laboratory, Weybridge, Surrey, UK; 6, R. M. Lemcke, Compton, Berkshire, UK.

A constant temperature of $10^{\circ} \mathrm{C}$ was maintained throughout with a refrigerated recirculator (Coolflow CFT-33, Neslab Instruments). After electrophoresis, the gels were stained for $16 \mathrm{~h}$ in a staining solution containing $0.1 \%$ (w/v) Page Blue $83(\mathrm{BDH})$ in an aqueous solution of methanol $(25 \%, \mathrm{v} / \mathrm{v})$ and acetic acid $(10 \%, \mathrm{v} / \mathrm{v})$. Gels were destained using the same solution, but with omission of the stain, until the background was clear, and were finally dried between dialysis membrane sheets (LKB 2003 slab gel dryer).

All chemicals used were the highest quality available (BDH). Acrylamide was Grade 1 quality; $N, N^{\prime}$ methylenebisacrylamide, TEMED, ammonium persulphate, and Page Blue 83 were 'Electran' grade; SDS was 'especially pure' grade; Tris and glycine were 'Analar' grade; and the $\mathrm{HCl}$ was volumetric grade. The water used was deionized (resistance $10 \mathrm{M} \Omega \mathrm{cm}^{-1}$ ). BDH molecular mass markers $(12.3$ to $78 \mathrm{kDa}$ ) were included in all runs for calibration purposes.

Scanning of gels. The stained protein patterns in the dried gels were scanned (Ultroscan 2202 laser densitometer; LKB-Produkter) at a scan speed of $20 \mathrm{~cm} \mathrm{~min}^{-1}$ and an absorbance range 0 to 1 . The absorbance values were 
recorded on magnetic disk (Apple Duodisk) as integers between 0 and 1000 using an interface program SCAN (Heyden Datasystems). and an Apple Ile microcomputer. The number of data points recorded along the length of the gel axis varied from 745 to 760 depending on the density of the protein bands on the original trace. The retention times and total areas of each protein band were calculated using an LKB 2220 recording integrator.

Computation. The raw data were carefully aligned and the initial (stacking gel/separation gel interface) and final (bromophenol blue marker) bands were deleted using Vidichart (Heyden Datasystems). The number of data points in each trace was reduced to a standard 500-point trace using an interpolation program (T PROCESS). A general background trend in each trace was removed to increase discrimination between patterns. The background cut-off was set at $0 \cdot 6$. Similarity between all possible pairs of traces was expressed using the Pearson product moment correlation coefficient. Strains were then clustered by the method of unweighted pair group average linkage (UPGMA) (Jackman et al. 1983). Interpolation, background trend removal, calculation of similarity and clustering were all done on an Apple IIe microcomputer using programs (T PROCESS, T MATRIX, T CLUSTER) originally written in PET Basic but adapted to run in Applesoft Basic. Full details of the programs and mathematical treatment of background in T PROCESS are given elsewhere (Jackman et al.. 1983).

\section{RESULTS}

One-dimensional SDS-PAGE of whole-cell protein extracts of 26 strains belonging to the 'Micoplasma mycoides cluster' (as defined in this study) and the reference strain of $M$. pneumoniae produced patterns containing 50-55 discrete bands corresponding to molecular sizes of 18 to $100 \mathrm{kDa}$ (Fig. $1 a, b$ ). Duplicate samples of the protein molecular mass marker set, run on different gels, gave a correlation coefficient $(r)$ of $95 \pm 1 \%$, indicating a high reproducibility for the method. In addition, duplicate samples of the mycoplasma proteins run on different gels gave $r$ values of $90-94 \%$, again indicating high reproducibility.

A numerical analysis (using the Pearson product moment correlation coefficient and UPGMA clustering) revealed four distinct clusters (phenons) at a similarity $(S)$ level of $70 \%$, only two strains ( $M$. capricolum YP and $M$. pneumoniae NCTC $\left.10119^{\top}\right)$ remaining outside these clusters. as indicated in the dendrogram (Fig. 2). Although the protein patterns of all $26^{\circ} \mathrm{M}$. mycoides cluster' strains were generally similar, with many shared common bands, each of the four phenons (1-4) also had proteins common only to its members and not shared by the other phenons. A degree of heterogeneity was also evident within each phenon and especially within phenons 2 and 3.

Comparison at the $75^{\circ}{ }_{0} S$ level gave a total of eight phenons, resulting entirely from division of phenons 2 (into $2 \mathrm{a} .2 \mathrm{~b}$ and $2 \mathrm{c}$ ) and 3 (into $3 \mathrm{a}, 3 \mathrm{~b}$ and $3 \mathrm{c}$ ). The average inter-and intra-phenon similarities are listed in Table 2 . The phenons recognized proved to be extremely stable when computations were repeated using different levels of trace alignment and background subtraction. The features of the various phenons are described below.

Phenon / (bovine group 7). All three strains of bovine group 7 mycoplasmas fell into phenon 1. The intra-group a verage similarity was $87.0 \pm 3.7 \%$, indicating a relatively homogeneous group with respect to overall protein pattern. The strains produced a distinctive high-intensity region $(46-50 \mathrm{kDa}$ ) (Fig. $1 a, b)$, comprising four overlapping bands $(46 \cdot 1,46 \cdot 8,48 \cdot 2$ and $49 \cdot 4 \mathrm{kDa}$ ) that accounted for $20-25 \%$ of the total protein content of each strain. Several of these bands were also represented in the protein profiles of other phenons (see below). A secondary band pattern, differing significantly from that of other phenons within the ' $M$. mycoides cluster', included bands at $65 \cdot 2,60 \cdot 0$ and $54 \cdot 4-53 \cdot 5 \mathrm{kDa}$ in the high molecular mass region and $43 \cdot 3,37 \cdot 5,35 \cdot 2,26 \cdot 4$ and $21.4 \mathrm{kDa}$ in the lower molecular mass region. Most of these positions were also represented in the patterns of strains in the other three phenons, but the $26.4 \mathrm{kDa}$ band appeared to be unique to the three bovine group 7 strains. The nearest neighbours of phenon 1 in terms of a verage similarity were phenon $2 \mathrm{~b}$ ( $M$. capricolum) and phenon 3a (M. mycoides subsp. mycoides LC/M. mycoides subsp. capri) with which it had similarities of 72.6 and $70.6 \%$, respectively.

Phenon 2 (F38/M. capricolum). At the $70^{\circ} \mathrm{S}$ level, nine of the ten strains previously assigned to these groups fell into phenon 2, the single exception being strain YP of $M$. capricolum, which remained unclustered. The high intra-phenon standard deviation (SD) of $8.2 \%$ and low average similarity of its members $(77.5 \%)$ reflected the appreciable degree of heterogeneity in protein patterns of this phenon. 


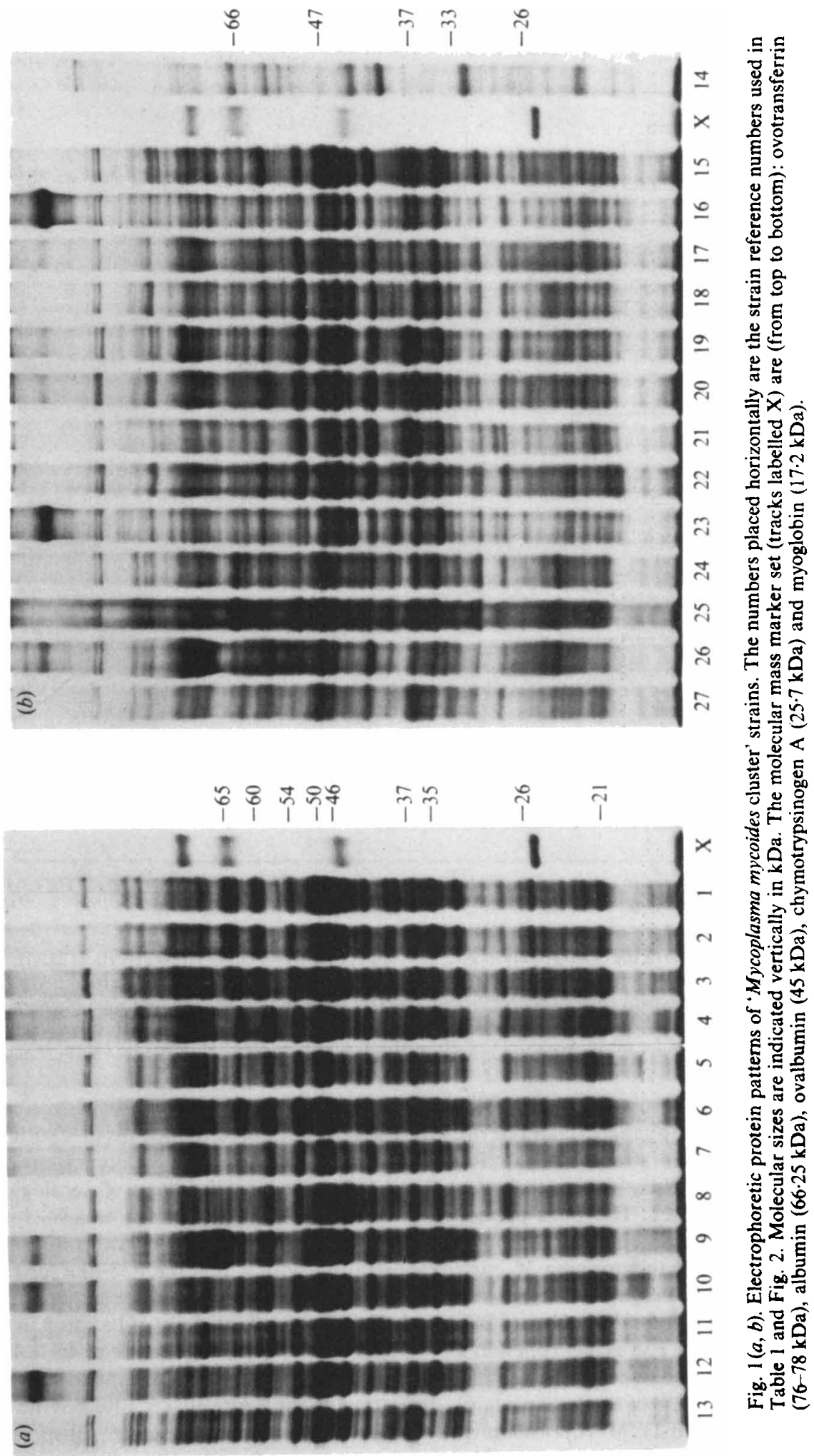




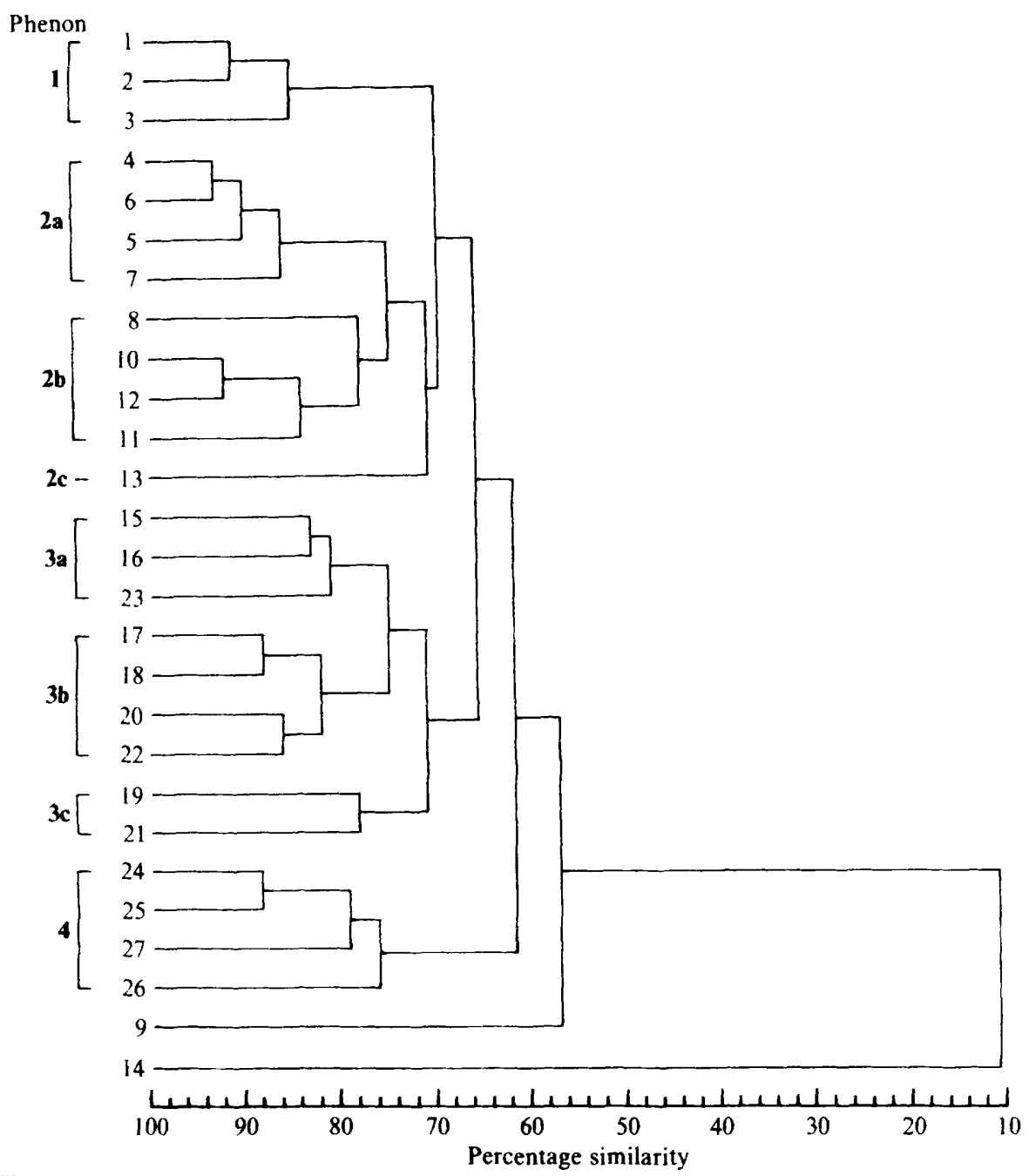

Fig. 2. Dendrogram of the cluster analysis based on total protein content of strains (vertical axis) listed in Table 1. The numbers on the horizontal axis indicate the percentage similarities as determined by the Pearson product moment correlation coefficient and UPGMA clustering. The indicated phenons are associated with the following: 1, bovine serogroup 7; 2a, F38-like group; $2 \mathrm{~b}$ and $2 \mathrm{c}, \boldsymbol{M}$. capricolum; $3 \mathrm{a}$, $3 \mathrm{~b}$ and $3 \mathrm{c}, M$. mycoides subsp. mycoides (LC strains) and subsp. capri; $4, M$. mycoides subsp. mycoides (SC strains).

At the $75 \% S$ level, phenon 2 could be further divided into three sub-phenons (a-c). Phenon $2 \mathrm{a}$ consisted of all four strains of the F38-like group, including the reference strain F38 (NCTC 10192) and three other strains previously identified on the basis of serological and biochemical properties. The intra-phenon average $S$ level for phenon 2 a was $88.3 \pm 2.8 \%$, confirming the homogeneity of the group. The protein patterns were in general similar to those of phenons $2 \mathrm{~b}$ and $2 \mathrm{c}$ (comprising $M$. capricolum strains), with which the F38-like (phenon $2 \mathrm{a}$ ) group strains had average similarities of 74.8 and $72.8 \%$ respectively. The major difference between the three phenons $(2 \mathrm{a}, 2 \mathrm{~b}$ and $2 \mathrm{c})$ was the lower overall intensity of banding in the 46 $50 \mathrm{kDa}$ region of the F38 group (phenon 2a) strains, characterized by bands at $46 \cdot 1,48 \cdot 2$ and $49.4 \mathrm{kDa}$. These bands accounted for $15 \%$ of the total proteins, with the band at $46.1 \mathrm{kDa}$ contributing only $1-2 \%$ of the total proteins, in contrast to the figure of $>5 \%$ for bovine group 7 mycoplasma (phenon 1), $M$. capricolum (phenons $2 \mathrm{~b}$ and $\mathrm{c}$ ) and $\boldsymbol{M}$. mycoides subsp. mycoides LC/M. mycoides subsp. capri (phenon 3). 


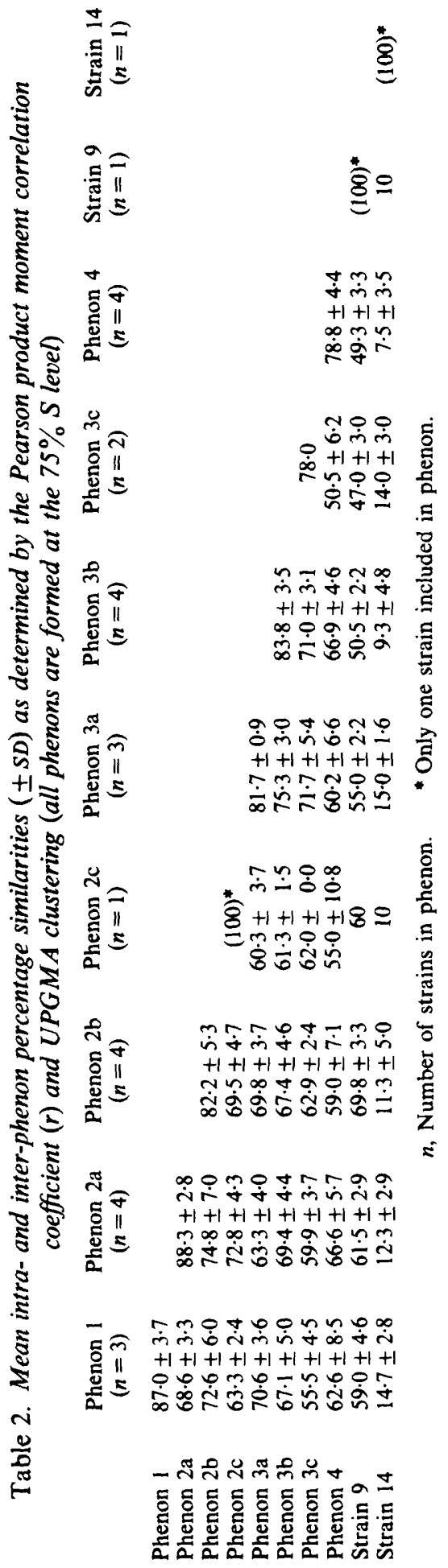


Phenon $2 b$ comprised four of the six $M$. capricolum strains and phenon $2 c$ contained only one strain. the type strain (NCTC 10154) for the species $M$. capricolum. Both phenons were similar to each other and to phenon $2 a$, sharing many common bands as reflected in the high interphenon similarities (Table 2). However, phenon $2 \mathrm{c}$ did differ significantly from both $2 \mathrm{a}$ and $2 \mathrm{~b}$ in its secondary banding pattern, having a more intense band at $37 \mathrm{kDa}(-12 \%$ of total protein $)$ as compared with a band of similar position, $37.4 \mathrm{kDa}$, in phenons $2 \mathrm{a}$ and $2 \mathrm{~b}(\sim 5 \%)$. In contrast, the band at $35.2 \mathrm{kDa}$ was weak for phenon $2 \mathrm{c}(<2 \%)$, but more intense for phenons $2 \mathrm{~b}$ $\left(610^{\circ}\right)$ and $2 \mathrm{a}\left(2-6^{\circ}{ }_{0}\right)$.

Phenon 3 ( $M$. mycoides subsp. mycoides LC and subsp. capri). The nine strains included in phenon 3 comprised all of those previously classified as either $M$. mycoides subsp. mycoides LC or $M$. mycoides subsp. capri. The intra-phenon average similarity of $75.8-5.8 \%$ indicated some heterugeneity within phenon 3 . At the $75 \% \mathrm{~S}$ level, this phenon could be further divided into three phenons (Fig. 2). The distribution of the nine strains among these three phenons appeared unrelated to previous identity: strains of $M$. mycoides subsp. mycoides LC were represented in 3a and $3 \mathrm{~b}$, and comprised $3 \mathrm{c}$, whereas strains of $M$. my coides subsp. capri were found only in $3 \mathrm{a}$ and $3 \mathrm{~b}$. The intra-phenon average similarities for phenons $3 \mathrm{a}, 3 \mathrm{~b}$ and $3 \mathrm{c}$ were $81 \cdot 7,83.8$ and $78 \%$ respectively, each thus showing an increase in homogeneity over that of the undivided phenon. The inter-phenon similarities, however. remained high (all $>70 \%$ ).

There appeared to be a greater diversity of patterns within phenon 3 than in phenon 2 , where diversity was due more to quantitative than to qualitative differences. This is seen clearly in the 47-37 $\mathrm{kDa}$ region of the phenon 3 patterns (Fig. $\mathrm{lb}$ ) where most of the diversity is found. The secondary banding pattern of phenon 3 also differed notably from phenons 1 and 2 in the lack of a band at $32.8 \mathrm{kDa}$.

Phenon 4 ( $M$. mycoides subsp. mycoides SC). Phenon 4 contained only strains previously identified as $M$. mycoides subsp. mycoides SC, including the type strain PGI (NCTC 10114). The average intra-phenon similarity was $78.8 \pm 4.4 \%$. The protein patterns were in general similar to those of the other phenons represented in this study, but with major differences in the banding region, $46.50 \mathrm{kDa}$, within which there was only one relatively intense band ( $49.4 \mathrm{kDa})$, which accounted for $69 \%$ of the total protein content. Although bands at $48 \cdot 2$ and $46 \cdot 1 \mathrm{kDa}$ were also present within this region, they were weak $(<2-3 \%)$ as compared with corresponding bands for other phenons.

M. capricolum (strain YP). This strain did not cluster with any of the phenons at either 70 or $75^{\circ} S$. Its pattern was, however, generally similar to those of $M$. capricolum phenon $2 \mathrm{~b}$ strains, except for a distinctive intense band $(66.5 \mathrm{kDa})$ accounting for $25 \%$ of the total protein and present exclusively in the pattern of this strain. A second analysis, excluding the band at $66.5 \mathrm{kDa}$, that compared $M$. capricolum strain $Y P$ with all other strains gave average similarities of $69 \cdot 6,73 \cdot 3.83 \cdot 5 \cdot 61 \cdot 2$ and $55 \cdot 5 \%$ with phenons $1,2 \mathrm{a}, 2 \mathrm{~b}, 3$ and 4 respectively. This analysis suggests that the presence of the heavy band at $66.5 \mathrm{kDa}$ in $\boldsymbol{M}$. capricolum YP had weighted the first analysis away from a clustering of this strain with members of the same species. The second analysis indicated that $M$. capricolum strain $Y \mathbf{P}$ is most similar to phenon $2 \mathrm{~b}(\boldsymbol{M}$. capricolum).

\section{DISCUSSION}

As at present envisaged (Cottew et al., 1987), the ' $M$. mycoides cluster' comprises six distinguishable mycoplasma groups, two being unnamed and four belonging to named species or subspecies. In our numerical analysis of 1-D SDS-PAGE protein patterns, all but one of the 26 strains of the cluster examined fell into taxonomic clusters that conformed with the existing classification at the $75^{\circ}$ o $S$ level, except that strains hitherto classified separately as $M$. mycoides subsp. mycoides LC and subsp. capri could not be clearly distinguished from each other.

Phenons $I$ and 2. The taxonomic position of bovine group 7 strains (phenon 1) has been problematical, largely because of the uncertain relationship of this group with $M$. mycoides 
(Leach, 1973). Although at the $70 \% S$ level the three representatives of this group that we examined fell into a cluster also containing F38 and $M$. capricolum, they formed a separate phenon, distinct from all others, at the $75 \% S$ level. This result is compatible with their being classified as a distinct species, as suggested by Salih et al. (1983) on the basis of the characteristic isoenzyme patterns of bovine group 7. Such a classification is consistent with reported DNA/DNA hybridization values of $58-64 \%$ between group 7 and other members of the ' $M$. mycoides cluster' (Christiansen \& Ernø, 1982), although a single higher value of $85 \%$ homology with $M$. mycoides subsp. mycoides SC has been reported (Askaa et al., 1978). Protein congruence determined from 2-D PAGE studies (Andersen et al., 1984; Nascimento et al., 1986; Rodwell, 1982) also places bovine group 7 strains roughly equidistant from the other cluster members. However, A. W. Rodwell's (personal communication) later revision of his data places bovine group 7 slightly closer to $M$. capricolum, in closer agreement with our present results (Fig. 2), which at the $70 \% S$ level place bovine group 7 (phenon 1) closest $(69.7 \% S$ ) to phenon 2 containing $M$. capricolum and F38 strains. The reported serological cross-reactivity of bovine group 7 with $M$. capricolum (Ernø et al., 1983) and with F38 (Cottew et al., 1987) endorses this limited relationship, but the overall evidence at present suggests bovine group 7 to be a separate taxon, although with similarities to $M$. capricolum and F38.

The DNA homology value for the $M$. capricolum and F38 type/reference strains was reported as $80 \%$ (Christiansen \& Ernø, 1982), this high value being consistent with their high protein pattern congruence (Andersen et al., 1984; Rodwell, 1982 and personal communication). Our PAGE findings are in general agreement with these reports in that the two mycoplasma groups constitute a single phenon (2) at the $70 \% S$ level but divide into separate phenons, $2 \mathrm{a}$ (F38), $2 \mathrm{~b}$ and $2 \mathrm{c}$ ( $M$. capricolum), at $75 \% S$. The single anomalous unclustered strain (YP) of $M$. capricolum proved to be most similar $(83.5 \% S)$ to the other five $M$. capricolum strains when a re-analysis that disregarded the $66.5 \mathrm{kDa}$ protein band was performed. This emphasizes the possibility of misidentification at and below the species level, if total protein PAGE patterns alone are used, with coefficients employing both qualitative and quantitative data, as already noted for Providencia spp. (Costas et al., 1987; Holmes et al., 1987). Although certain biochemical and growth characteristics serve to separate the $M$. capricolum and F38 groups, there are serological similarities between some strains of each (Ernø et al., 1983; Cottew et al., 1987). These and their genomic similarities, taken together with our protein pattern results, tend to place both within a single taxon, but as distinguishable groups, in accordance with the suggestion (Christiansen \& Ernø, 1982) of F38-like strains as a possible subspecies of $M$. capricolum. Further DNA homology studies on selected representatives of these two groups, as recently proposed (Cottew et al., 1987), should help to resolve finally this taxonomic issue, which has important veterinary implications.

Phenons 3 and 4. With regard to mycoplasmas at present comprising the species $M$. mycoides, the striking result is that, even at low levels of similarity $(<65 \% S)$, all four strains of the classical SC type of subsp. mycoides were clearly separable (as phenon 4) from all other groups and were quite distinct from phenon 3 containing both subsp. capri and the LC strains at present assigned to subsp. mycoides. These two groups formed a single phenon (3) at the $70 \% S$ level and could not be clearly separated from each other even at the $75 \% S$ level, where they fell heterogeneously into three sub-phenons. The type/reference strains of subsp. mycoides, SC (PG1) and LC (Y goat), and of subsp. capri (PG3) were reported (Askaa et al., 1978) to be closely interrelated by DNA hybridization comparisons, with values of $90 \%$ for $\mathrm{Y}$ goat and PG1 and $80 \%$ for PG1 and PG3, although somewhat lower values $(75 \%)$ have been found for the latter pair (Andersen et al., 1984). Contrary to these results but consistent with ours, an extensive analysis of 28 strains by 2-D PAGE protein patterns (Rodwell, 1982) indicated that the LC strains of subsp. mycoides are more closely related to subsp. capri than to SC strains of subsp. mycoides. Nascimento et al. (1986) endorsed this finding in studies of field isolates from cases of caprine mycoplasmosis and also demonstrated the existence of strains intermediate between subsp. mycoides LC and capri, and less related to subsp. mycoides SC, both serologically and by their $2-\mathrm{D}$ protein patterns. Serological difficulties in distinguishing between some LC and capri 
strains are not surprising, in view of the complete overlap between the two groups in our results. It seems likely that, in the past, the allocation of isolates to one or other subspecies of $M$. mycoides, and particularly to subsp. capri, might sometimes have been somewhat arbitrary and perhaps influenced by the clinical background. The taxonomic confusion between these two groups is evident, in that two of the three sub-phenons they formed at the $75 \% S$ level contained strains from each group. More extensive 1-D PAGE studies, with a wider range of isolates representing these two groups, are underway, but it is already evident that some taxonomic revision will be needed that will reflect their close similarity. Such a reclassification should probably include the LC and subsp. capri strains within a single major taxon clearly separate from that of the SC (subsp. mycoides) strains. The taxonomic level of this separation would best be determined by more extensive DNA-homology studies on each group. Meanwhile, we are extending the comparisons between the two groups by further 1-D PAGE studies on a wider selection of isolates from each.

In conclusion, our analysis of 1-D protein patterns of the ' $M$. mycoides cluster' throws some light on the main problem areas as outlined in the Introduction. (1) The classical SC strains of $M$. mycoides subsp. mycoides are distinct from the LC strains, which ought therefore to be separated from this subspecies. (2) The close relationship between the LC strains and $M$. mycoides subsp. capri is confirmed, but requires further analysis. (3) Bovine group 7 strains appear to have distinctive protein patterns, although being most similar to $M$. capricolum and F38 strains, which are themselves closely related. We interpret our results as pointing towards the future division of the ' $\boldsymbol{M}$. mycoides cluster' into four major taxa, conceivably separate species, and comprising: (a) SC strains of $M$. mycoides subsp. mycoides; (b) LC strains of subsp. mycoides, together with those of subsp. capri (further sub-division of this taxon to be determined); (c) $M$. capricolum together with F38-type strains, each as potential subspecies; $(d)$ bovine group 7 strains. Authoritative decisions on final taxonomy will await further studies, including more comprehensive PAGE studies of protein patterns and, more particularly, DNA-homology studies upon a wider selection of strains from each of the existing six groups of the ' $M$. mycoides cluster'. Meanwhile, at a more practical level, it is apparent that numerical analysis of 1-D SDSPAGE patterns of mycoplasmal cellular proteins provides a useful approach towards clarifying relationships within the 'M. mycoides cluster'.

We would emphasize that a high level of pattern reproducibility, both within and between gels, is essential for such studies to be reliable and that this can be attained if the methods described here are adhered to strictly.

\section{REFERENCES}

Andersen, H., Christiansen, G. \& Christiansen, C. (1984). Electrophoretic analysis of proteins from Mycoplasma capricolum and related serotypes using extracts from intact cells and from minicells containing cloned Mycoplasma DNA. Journal of General Microbiology 130, 1409-1418.

AskaA, G., ERnб, H. \& Ojo, M. O. (1978). Bovine mycoplasmas: classification of groups related to Mycoplasma mycoides. Acta veterinaria scandinavica 19, 166-178.

Christiansen, C. \& ERnø, H. (1982). Classification of the F38 group of caprine mycoplasma strains by DNA hybridization. Journal of General Microbiology 128. 2523-2526.

Costas, M., Holmes, B. \& Sloss, L. L. (1987). Numerical analysis of electrophoretic protein patterns of Providencia rustigianii strains from diarrhoea and other sources. Journal of Applied Bacteriology (in the Press).

Cottew, G. S. \& Yeats, F. R. (1978). Subdivision of Mycoplasma mycoides subsp. mycoides from cattle and goats into two types. Australian Veterinary Journal 54, 293-296.
Cottew, G. S., Bréard, A., DA Massa, A. J., ERNø, H., LeACH, R. H., LefeVre, P. C., Rodwell, A. W. \& SMITH, G. R. (1987). Taxonomy of the Mycoplasma mycoides cluster. Israel Journal of Medical Sciences 23, 632-635.

Edward, D. G. FF. \& Freundt, E. A. (1969). Classification of the Mycoplasmatales. In The Mycoplasmatales and the L-phase of Bacteria, pp. 147-200. Edited by L. Hayflick. New York: AppletonCentury-Crofts.

ERnб, H., Leach, R. H., Salih, M. M. \& Macowan, K. J. (1983). The F38-like group, a new group of caprine mycoplasmas? Acta veterinaria scandinavica 24, 275-286.

Freund, E. A. \& Edward, D. G. FF. (1979). Classification and taxonomy. In The Mycoplasmas, vol. 1, pp. 1-41. Edited by M. F. Barile \& S. Razin. London: Academic Press.

Hayflick, L. (1965). Tissue cultures and mycoplasmas. Texas Reports on Biology and Medicine 23, 285303 (Suppl. 1).

Holmes, B., Costas, M. \& Sloss, L. L. (1987). Numerical analysis of electrophoretic protein pat- 
terns of Providencia alcalifaciens strains from human faeces and veterinary specimens. Journal of Applied Bacteriology (in the Press).

JaCkman, P. J. H., Feltham, R. K. A. \& SNeath, P. H. A. (1983). A program in BASIC for numerical taxonomy of micro-organisms based on electrophoretic protein patterns. Microbios Letters 23, 87-98.

LEACH, R. H. (1973). Further studies on classification of bovine strains of Mycoplasmatales, with proposals for new species, Acholeplasma modicum and Mycoplasma alkalescens. Journal of General Microbiology 75, 135-153.
Nascimento, E. R., Nascimento, M. DA G. F., FREUNDT, E. A. \& ANDERSEN, H. (1986). Isolation of Mycoplasma mycoides from outbreaks of caprine mycoplasmosis in Brazil. British Veterinary Journal 142, 246-257.

RODWELL, A. W. (1982). The protein fingerprints of Mycoplasmas. Reviews of Infectious Diseases 4, S8S17.

Salih, M. M., Simonsen, V. \& ERnø, H. (1983). Electrophoretic analysis of isoenzymes of $\mathrm{Myco}$ plasma species. Acta veterinaria scandinavica 2A, 1433. 